\title{
Muséologies
}

Les cahiers d'études supérieures

\section{Voici Muséologies}

\section{Alessandra Mariani}

Volume 1, numéro 1, octobre 2006

URI : https://id.erudit.org/iderudit/1033652ar

DOI : https://doi.org/10.7202/1033652ar

Aller au sommaire du numéro

Éditeur(s)

Association Québécoise de Promotion des Recherches Étudiantes en Muséologie (AQPREM)

ISSN

1718-5181 (imprimé)

1929-7815 (numérique)

Découvrir la revue

Citer ce document

Mariani, A. (2006). Voici Muséologies. Muséologies, 1(1), 6-7.

https://doi.org/10.7202/1033652ar d'utilisation que vous pouvez consulter en ligne.

https://apropos.erudit.org/fr/usagers/politique-dutilisation/ 
Voici

Muséologies

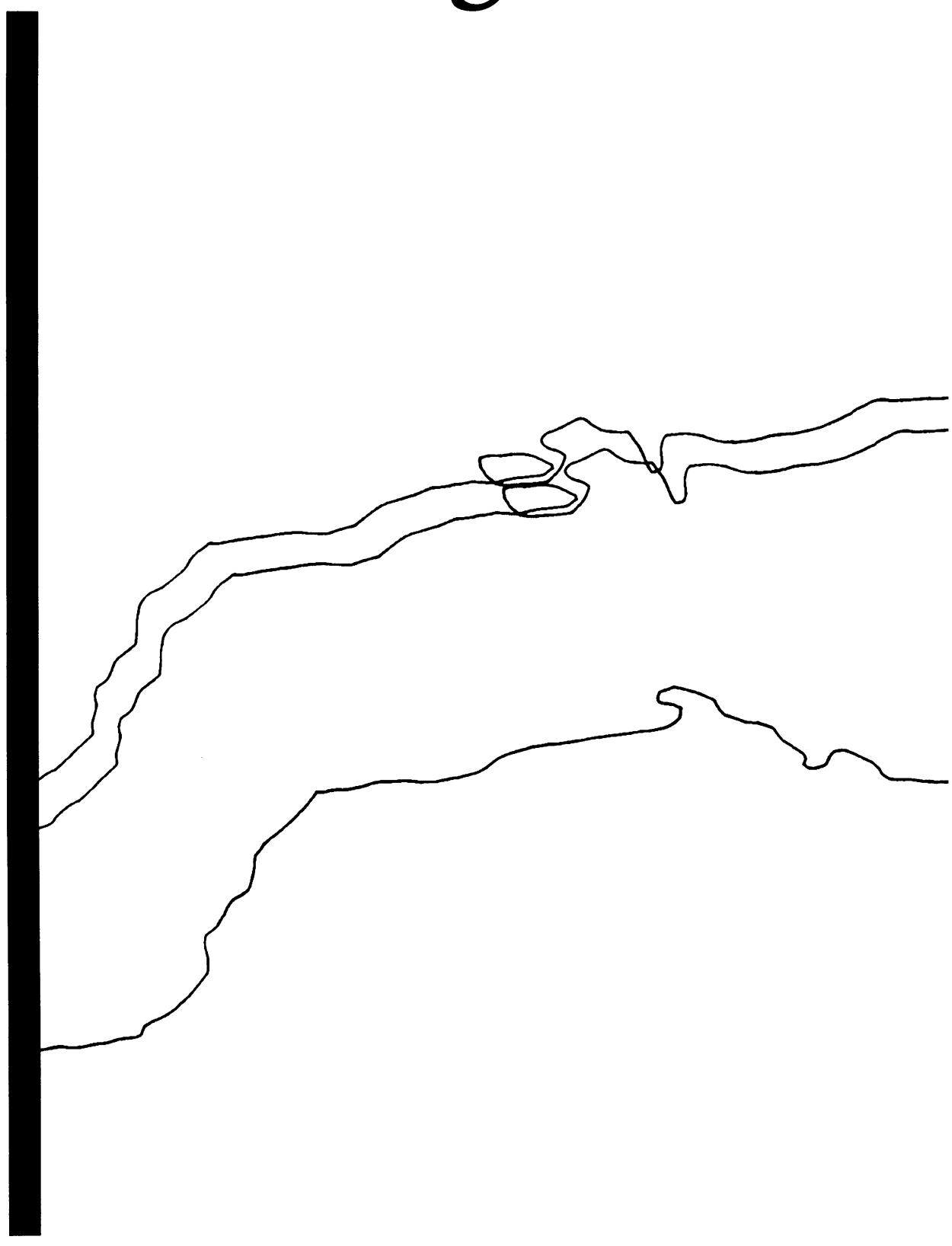


En janvier dernier, M. Yves Bergeron, professeur au département d'histoire de l'art de l'Université du Québec à Montréal (UQÀM) avait proposé - à qui voulait bien l'entendre - de créer une publication du type des Cahiers du Musée de la civilisation. Ces cahiers permettaient de diffuser annuellement un ou deux travaux inédits issus des programmes des cycles supérieurs en muséologie de l'UQÀM, de l'Université de Montréal et de l'Université Laval et qui méritaient d'être diffusés.

Cette idée a trouvé un écho auprès d'étudiantes et de diplômées qui se sont impliquées à la concrétiser. En s'inspirant de la formule initiale des cahiers, nous avons élaboré une nouvelle ligne éditoriale (trois à cinq articles publiés deux fois l'an), imaginé un nouveau format et ciblé un public plus large. Avec ces intentions, tout était à faire, et nous voulions tout refaire, du fond à la forme en offrant la possibilité à plusieurs voix de s'exprimer de façon conviviale sans se départir de la validation scientifique des travaux. Cette rigueur a été un des premiers soucis de l'équipe et le restera grâce à la collaboration soutenue de professeurs et de spécialistes du domaine. Muséologies - première publication universitaire d'études supérieures en muséologie au Québec - s'écrit au pluriel, et il est essentiel de souligner ce caractère. Ce " $s$ " reflète la pluridisciplinarité et l'interdisciplinarité, les composantes essentielles de tout projet muséal actuel. Dans cet esprit, Muséologies veut développer la synergie entre le monde professionnel et la formation universitaire en portant de nouveaux regards sur l'organisation muséale, en livrant des

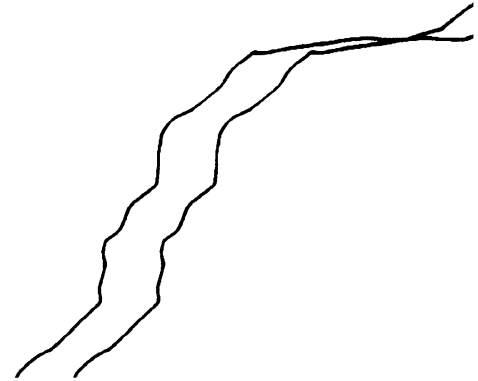

réflexions théoriques, des suggestions d'applications originales et des résultats d'enquêtes de terrain rigoureuses. Reflétant la polyvalence du milieu, ces articles issus de travaux de recherche mettront à profit les tendances émergentes.

Présenter ce premier numéro de Muséologies est un privilège légué par quatorze collègues au dynamisme et aux compétences incomparables. Ce projet n'aurait pu voir le jour sans toutes ces têtes et ces mains. Je leur rends hommage et en leur nom, je remercie avec empressement tous ceux et celles (professeurs, universités, commanditaires, organismes et bénévoles) qui ont contribué de près ou de loin à la réussite de cette aventure. À la Société des musées québécois, à l'Institut du Patrimoine de l'UQÀM, qui nous ont offert un très grand soutien, nous témoignons toute notre reconnaissance.

À vous public, je souhaite une excellente lecture.

Alessandra Mariani Éditeur

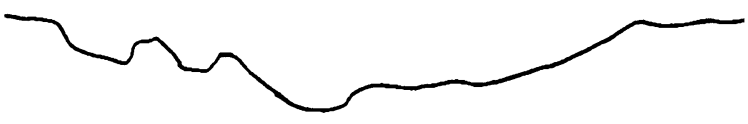

